\title{
Optimal contribution margin in food service using inventory control with statistical dependence
}

\author{
Márgenes de contribución óptimos en servicios de alimentación usando control de \\ inventarios con dependencia estadística
}

\author{
Fernando Rojas ${ }^{1,2 *}$
}

Recibido 21 de julio de 2017, aceptado 19 de febrero de 2018

Received: July 21, 2017 Accepted: February 19, 2018

\begin{abstract}
RESUMEN
En esta revisión comparamos diferentes modelos estadísticos que optimizan los márgenes de contribución de empresas de servicios de alimentos que producen raciones de alimentos, denominadas menús, basadas en materias primas denominadas componentes.

Esta revisión tiene como objetivo comparar el control de inventario de los servicios de alimentación considerando la demanda aleatoria de los componentes y la estructura de dependencia estadística respecto a componentes con demanda independiente. La dependencia estadística entre las demandas de componentes y/o menús se incorpora mediante la distribución gaussiana (o normal) multivariante, mientras que la demanda independiente de componentes se considera univariada normal. La optimización de los márgenes de contribución se logra utilizando modelos probabilísticos para cada inventario de componentes, encontrando políticas óptimas usando un algoritmo de evolución diferencial. Maximizamos los márgenes medios de contribución en un $18,32 \%$ y un $8,34 \%$ utilizando modelos de revisión continua en abarrotes y modelos de uni-período para componentes perecederos, al comparar resultados con y sin dependencia estadística de la demanda de componentes, respectivamente. Se discuten las direcciones futuras.
\end{abstract}

Palabras clave: Dependencia estadística, distribuciones multivariadas, márgenes de contribución, métodos de optimización, modelos de inventario probabilísticos.

\begin{abstract}
In this review we compared different statistical modeling that optimize the contribution margins of food services companies that produce food rations called menus based on raw materials denominated components. This review aims to compare inventory control for food services considering random demand and structure dependence regarding independent demands of the components. The statistical dependence between demands for components or menus is incorporated by Gaussian (or normal) distribution multivariate, while independent demand for components is considered normal univariate. Optimization of contribution margins is achieved using probabilistic models for each component inventories and finding optimal policies by the differential evolution algorithm. We maximize average contribution margins in an $18.32 \%$ and $8.34 \%$ using models of continuous review for groceries and single-period for perishable components with and without statistical dependence on demand, respectively. Future directions are discussed.
\end{abstract}

Keywords: Contribution margins, multivariate distributions, probabilistic models inventory, optimization methods, statistical dependence.

1 Facultad de Farmacia. Escuela de Nutrición y Dietética. Universidad de Valparaíso. Valparaíso, Chile. E-mail: fernando.rojas@uv.c

2 Facultad de Farmacia. Centro de Micro-Bio Innovación. Universidad de Valparaíso. Valparaíso, Chile

Autor de correspondencia. 


\section{INTRODUCTION}

Collective food services are mostly considered in the group of small and medium enterprises [47]. Many of these Chilean services are not optimizing their supply of raw materials. These materials form the inventory assortment, which is divided in perishable (as fruits, meats, vegetables) and non-perishable products with greater storing capacity subject to shortage; see [14]. Logistics of these raw materials are based on the monthly planning of the menu, which are guided by nutritional considerations. However, this management can be improved by using inventory control policies, which allows contribution margins (CMs) the company to be increased; see [36] and [26] for a case study in hotels. $\mathrm{CMs}$ are the gross profits of a company and summarize the movements of income and cost, which may be direct (variable costing) and indirect (absorption costing). These margins vary depending on sold units, unit costs of the product, the ratio between them and the total costs and fixed costs involved; see [29].

Inventory control policies reduce the vulnerability of supply chain management in enterprises. Reduction of inventory is crucial in operation management. In this way, these strategies are focused in optimizing inventory levels to meet the demand of components and final products of the companies satisfying customers [16]. To optimally manage inventory, organizations need to investigate processes and model them in all its phases, using appropriate methodologies [22]. Several authors have discussed the importance for companies to manage their inventories optimally as input logistically efficient management [19]. This optimal administration also should be considered by food services companies [30].

Generally, stochastic inventory models consider the demand for products as a random variable (RV) described by a continuous or discrete distribution. To optimize total costs (TC) of inventory its necessary understand their composition. Three components constitute the TC: (a) a cost that is independent of the lot size, (b) a cost that depends on the quantity of products in the lot, and (c) a cost of shortage due to unsatisfied demand [13]. Once the inventory model indicators have been defined and distributional assumptions for demand per unit time (DPUT) and demand during lead-time (LT), in short LTD, have been established, the expected value of the objective function based on the TC of the inventory must be optimized [25]. Thus, modeling correctly the demand regarding probability distribution its necessary to optimize total cost of inventory.

Treatment of DLT when LT is constant is relatively easy but a large part of DPUTs, however often DPUTs are not independent and identically distributed (IID) RVs. An easy view is estimate mean and variance of the DPUTs of components can be used in models of inventory control continuous review or perishable components, minimizing the total annual costs (TCs) associated with the purchase, storage, generation of purchase orders and shortages of components [35]. Subtracting the TCs brought to sales revenues for each component that makes up the menus, it is possible to maximize the CMs of the food service, as was demonstrated in the study by [32-33]. However, in food service the demands have statistical dependence because their components (different foods that compose the menu) are correlated, or are correlated with menus. For this, the classic view of inventory control using mean, variance and univariate distribution is incorrect [32]. When you want to optimize inventory composed of multiple components, as in the case of food service, you can omit the possible statistical dependence between the demands for these components and perform optimization. In general, CMs tend to increase despite this omission, as demonstrated [33]. However, [32] improve the optimization of CT using multivariate probability distribution based in [20] So, considerate correlations and dependence between products can be produce less CT.

This study aim to compare inventory control models with random demand and dependence structure concerning models with random but independent demand and its effect on the CMs of food services. This paper is organized as follows: Section 2 makes a literature review about: (i) modeling of DPUT of components with statistical dependence; (ii) inventory control models; (iii) stochastic programming; and (iv) financial indicators of the inventory policy. Section 3 exposes the proposed methodology, whereas Section 4 illustrates it with a real-world case study of Chilean foods service; and Section 5 provides conclusions of the results obtained in this review, as well as their limitations and future research.

\section{LITERATURE REVIEW}

\section{Modeling DPUT and DLT with statistical dependence}

The study of the uncertainty of DPUT and DLT is a key issue not only for retailers but also for 
supply chain management [13]. This uncertainty is present because the DPUT and DLT usually occur in a stochastic manner. Therefore, the DPUT and DLT are RVs that follow univariate probability distributions [17]. The DLT corresponds to a sum of independent DPUTs, generally understood as a series of uncorrelated demand time, and is useful to determine the components of inventory control models [45]. In LT constant scenario DLT is easier to calculate and use normal (or Gaussian) distribution to describe. Gaussian (or normal) distribution is often used to describe the DPUT because of its simple mathematical treatment, its attractive properties and its computational implementation in different software [17]. However, to calculate optimal inventory, its necessary select an appropriate probabilistic distribution of DPUT through goodness of fit methods [2]. The interested reader can review a summary provided in Table 1 of the article [9] to see details of other probability distributions used in inventory control models with random demand. According [10], in multi-product supply systems, the correlation between de mands by components affects system CTs. In the context of correlated demands, [43] established the need to model the dependence structure of variables to be considered in an optimization model. Thus, in this review we compared the results of MCs with the methodology proposed by [33] for independent demands in food service and the extension to the dependent case [32].

\section{Inventory control models in food service}

An optimal inventory policy can be attained choosing an adequate inventory model, whose decision involves several aspects; see [4-6, 41-42]. In the case of non-perishable products, inventory models would be classified in pull or push, which range from the economic order quantity (EOQ) to the just in time (JIT) supply; see [40]. The EOQ model is the cornerstone of several software packages for inventory control and is widely used in practice; see [24]. The JIT method is useful for raw materials that can be supplied as timely as they are required, although it imposes constraints to the logistics limiting its use for some types of products in food services; see [8,40]. Several scholars seek a EOQ (Q) model with a reorder point (ROP) (r) that would be appropriated in food service. In this way, continuous review-based inventory models called $(\mathrm{Q}, \mathrm{r})$ models are used for supply planning and demand. Considering lead time (LT) in the modelling makes the assumptions of the model to be more adherent to real world settings; see [3]. The EOQ model is used altogether with the ROP in inventory control to determine safety stocks (SS) under both random LT and demand, which randomness directly affects the operation of a logistics system; see $[37,40]$. When calculating the reorder point for a fixed service level, the LTD distribution and its corresponding probability density function (PDF) must be used. When the LTD distribution is unknown, this PDF can be approximated by any suitable approach. In this review, we use a simultaneous approach to optimize $\mathrm{Q}$ and $\mathrm{r}$ as recommended by $[35,46]$. Perishable (single-period) are more complicated because these products can be stored during a limited period. These components usually correspond to fruits, meats and vegetables, which are essential raw materials in food service. When these types of components are considered, the model based on the critical ratio (CR) or service level is often considered; see [16].

Through inventory control models for each component it is possible to maximize the annual MCs from the sale of menus [33]. Overall, as revenues from this sale does not depend on the model applied to each component, the CMs are maximized by finding the minimum inventory TCs [16]. These TCs are obtained taking stochastic inventories control models of continuous review and single period applied to each component [33]. According [35], the optimal quantity to supply in this inventories control models determinates the TCs relative to purchase, holding, generation of order purchase and penalty for shortage of components. All these TCs are functions of parameters univariate or multivariate probability distributions of DPUT, LT and DLT [45]. According to inventories control models, this functions correspond to mean, variance, percentiles or other indicators, estimates through statistical methods [31, 33, 45]. Thus, its necessary separate inventory models in perishable and non-perishable components. In this review we compared inventories control models with stochastic demand of multiple components with or without statistical dependence.

\section{Stochastic programming}

Stochastic programming is a mathematical programming problem (linear, nonlinear, integer, and so on.) which contains in its formulation some stochastic element that is unknown, but that can be estimated from its probability distribution 
[34]. The expected value of the objective function based on the TC of inventory must be optimized in a continuous review policy of an assortment of products. Stochastic programming can be used to solve this optimization problem by the differential evolution (DE) algorithm, which belongs to the family of genetic algorithms, imitating the natural process of choice in evolutionary fashion $[28,39$, $46,32)$. In this paper review algorithm DE is used to optimize the problem of stochastic programming associated with inventory control models considered.

\section{Financial indicators of the inventory policy}

The economic benefits of inventory models are evaluated by efficiency indicators. Some of them are financial, such as TCs from inventories or sales related to the rotation of stocks available; whereas others are operational, such as the ability to meet demand with inventory planned by the inventory model (called "fill-rate"), or the expected shortage per cycle [46]. This paper review addresses the CMs as a financial indicator of inventory management of each storage component [33].

\section{METHODOLOGY}

\section{Assumptions and limitations}

Assumptions: (i) the DPUT for a component or menu go to RV with normal distribution; (ii) this DPUT is a sequence of values over time without seasonality and trend; (iii) the DPUT can have dependence of the DPUT of other component or of a menu that contain the first component; (iv) the dependence is described by Pearson correlation coefficient; (v) the LT is constant; and (vi) the unitary cost of purchase, unitary annual holding cost, order cost and penalty for shortage cost is predetermined by managers of food service. Limitations: Is necessary additional research to improve results. For example, to incorporate time dependence of the DPUT; the use of others probabilistic distributions; also assume random LT with some probabilistic distribution.

\section{Univariate Distribution of DPUT}

Let $\mathrm{Y}_{\mathrm{t}}$ be a RV corresponding to the DPUT (Y) of a component at the time t. Furthermore, let the RV L be the LT (lead time) of an item, which not dependent from the sequence of independent identically distributed $R V s\left\{Y_{t}, t \geq 0\right\}$, where $E\left(Y_{t}\right)=$ $\mathrm{E}(\mathrm{Y})=\mu$ and $\operatorname{Var}\left(\mathrm{Y}_{\mathrm{t}}\right)=\operatorname{Var}(\mathrm{Y})=\sigma^{2}$ are the mean and variance of the DPUT, respectively. Suppose that the orders do not have crossbreeding [15]. Furthermore, let 1 the LT constant and D the DLT of component. Assume that 1 is independent of sequence $\{\mathrm{Yt}, \mathrm{t} \geq 0\}$, it must

$$
D=\sum_{t=1}^{l} Y_{t}
$$

As is common in inventory models, it is assumed that the DLT is a continuous random variable with probability density function (PDF), cumulative distribution (CDF) and quantile (QF) given respectively by equation (1)

$$
f_{d}(d), d>0, \mathrm{~F}_{D}(d)=\int_{0}^{d} f_{(D)}(v) d v, D(q)=F_{D}^{-1}(q), 0<q<1
$$

here $\mathrm{F}_{\mathrm{D}}^{-1}$ is the inverse function of $\mathrm{F}_{\mathrm{D}}$. The mean and variance of $\mathrm{D}$ are expressed as equation (2) and equiation (3) respectively

$$
E(D)=E(l) E\left(Y_{t}\right)=E(l) \mu
$$

$$
\operatorname{Var}(D)=\operatorname{Var}(l) E^{2}\left(Y_{t}\right)+E(l) \operatorname{Var}\left(Y_{t}\right)=\operatorname{Var}(l) E^{2}\left(Y_{t}\right)+E(l) \sigma^{2}
$$

As LT is constant and equal to 1 , it is, $\operatorname{Var}(1)=0$, the expression gives in (2) and (3) is reduce to $E(D)=1 \mu$ and $\operatorname{Var}(\mathrm{D})=1 \sigma^{2}$ respectively. Analogously, at time $\mathrm{t}$, the DPUT another associated component with $Y_{t}$, or the DPUT of a menu conformed by first component, is denoted in general by $\mathrm{X}_{\mathrm{t}}$. Notice that $\mathrm{X}_{\mathrm{t}}, \mathrm{Y}_{\mathrm{t}, \mathrm{l}} \mathrm{l}$ and $\mathrm{D}$ can be modelling by discrete or continues probabilistic distributions. As assume 1 is constant and that DPUTs $\mathrm{X}_{\mathrm{t}}$ are $\mathrm{Y}_{\mathrm{t}}$ continues RVs with PDFs $\mathrm{f}_{\mathrm{x}}$ and $\mathrm{f}_{\mathrm{y}}, \mathrm{CDFs} \mathrm{F}_{\mathrm{x}}$ and $\mathrm{F}_{\mathrm{y}}, \mathrm{QFs} \mathrm{F}_{\mathrm{X}}{ }^{-1}$ and $\mathrm{F}_{\mathrm{Y}}{ }^{-1}, \mathrm{E}\left(\mathrm{X}_{\mathrm{t}}\right)=$ $\mu_{\mathrm{x}}$ and $\mathrm{E}\left(\mathrm{Y}_{\mathrm{t}}\right)=\mu_{\mathrm{y}}, \operatorname{Var}(\mathrm{X})=\sigma_{\mathrm{x}}^{2}$ and $\operatorname{Var}(\mathrm{Y})=\sigma_{\mathrm{y} \cdot}^{2}$. Also normal distributions are assumed for $\mathrm{X}_{\mathrm{t}}$ are $\mathrm{Y}_{\mathrm{t}}$. To model probabilistic distribution of DPUT for each component appropriate data should be collected. So, the parameters of normal distribution must be estimated and the good of fit must be evaluated to diagnostic its suitability [33].

\section{Bivariates and conditional distributions of DPUTs} Let $Y_{t}$ the DPUT of a component and $X_{t}$, the DPUT of other component or menu at time $t$, as they were defined in the previous subsection. Assume that these RVs conformed a random vector bivariate $\left(\mathrm{X}_{\mathrm{t}}, \mathrm{Y}_{\mathrm{t}}\right)$ with joint $P D F f_{x, y}$, with dependence between $X_{t}$ and $Y_{t}$ described by the Pearson correlation coefficient 
@X,Y $\in[-1,1]$. So, the PDF $Y_{t}$ conditional to $X_{t}=x$ it is given by equation (4)

$$
f_{Y / X=x}(y)=f_{X, Y}(x, y) / f_{x}(x), x \in R_{x}, y \in R_{Y}
$$

Where $R_{X}$ and $R_{Y}$ are the possible relationships of $R V s X_{t}$ and $Y_{t}$, respectively. Thus, from 4, obtain the expected value as equation (5)

$$
\mathrm{E}\left(\mathrm{Y}_{t} / X_{t}=x\right)=\int_{R_{Y}} y f_{Y / X=x}(y) d y
$$

Moreover, it is known that $\operatorname{Var}\left(\mathrm{Y}_{\mathrm{t}} / \mathrm{X}_{\mathrm{t}}=\mathrm{x}\right)=\mathrm{E}\left(\mathrm{Y}_{\mathrm{t}}^{2} /\right.$ $\left.\mathrm{X}_{\mathrm{t}}=\mathrm{x}\right)-\left(\mathrm{E}\left(\mathrm{Y}_{\mathrm{t}}^{2} / \mathrm{X}_{\mathrm{t}}=\mathrm{x}\right)\right)^{2}$. So, for this conditional variance should be calculated as equation (6)

$$
\mathrm{E}\left(\mathrm{Y}_{t}^{2} / X_{t}=x\right)=\int_{R_{Y}} y^{2} f_{Y / X=x}(y) d y
$$

For the case where $\left(X_{t}, Y_{t}\right)$ follow a bivariate normal distribution with means $\mu_{X}$ and $\mu_{Y}$, variances $\sigma_{x}^{2}$ and $\sigma_{\mathrm{y}}^{2}$, and correlations coefficients $\rho_{\mathrm{X}, \mathrm{Y}}$, from equiation (5) and equation (6) the conditional expected value is calculated as equation (7)

$E\left(Y_{t} / X_{t}=x\right)=\mu_{Y}-\rho_{X, Y} \frac{\sigma_{Y}}{\sigma_{X}}\left(x-\mu_{X}\right), \operatorname{Var}\left(Y_{t} / X_{t}=x\right)=\sigma_{Y}^{2}\left(1-\rho_{X, Y}\right)$

As shown in equation (7), the expected value and variance of DPUT $Y_{t}$ of a component depend of the value to conditioning $X_{t}=x$, which could take various values. However, for practical purposes a single value is needed. To solve this problem, it is proposed to take the sample values of $X_{t}$ to find the conditional expected value. By using this procedure in stochastic optimization of the objective function, different optimal values for a range of possible values of $X_{t}$ will be obtained. Then, you can use the value of $X_{t}$ to condition like a deterministic value, providing the optimum value of the objective function. Thus, the expression given in equation (7) serves to establish the rate of conditional demand for a component to be used in inventory control model in food service with statistically dependent demand.

\section{Stochastic programming of inventories control models in food service}

The problem of stochastic programming to be formulated should consist of: (i) decision variables involved in each model associated with inventory control to optimize the component; and (ii) maximize the objective function corresponding to the CMs, based on each model. This objective function contains indicators dependent probabilistic inventory model that make it stochastic mathematical programming. In all models used inventory is considered to be a group of components in order to minimize the expected annual TC assuming shortage. The TC expected for component $i$ expressed as the sum of the costs (in monetary units): (i) purchase by the total of component $\left(C_{i}\right)$ supplied annually, given by the multiplication of the annual demand for the component unit cost $\left(c_{i}\right)$; (ii) generation of purchase orders by the total orders $\left(O_{i}\right)$ a year, given by the multiplication of the number of orders issued in one year by the unit cost of each order $\left(o_{i}\right)$; (iii) storage medium component $\left(A_{i}\right)$ a year, given by multiplying the average number of annual units stored by the storage unit annual cost component $\left(a_{i}\right)$; and (iv) of shortages (shortage or break) total component $\left(S_{i}\right)$ a year, given the expected amount of shortage per cycle multiplied by the number of cycles of shortages in a year by the unit cost of shortage of component $\left(s_{i}\right)$. It is assumed that in the food service has a permanent demand 365 days a year. For inventory control model indicated below, the stochastic programming problem is formulated as:

$$
\begin{array}{ccc} 
& \begin{array}{l}
\text { Continues review model } \\
\text { (groceries) }
\end{array} & \begin{array}{l}
\text { Perishable in single } \\
\text { period model } \\
\text { (fruit, vegetable and } \\
\text { meats) }
\end{array} \\
\text { Objetive function } & \min _{i=1}^{c} E\left(T C\left(Q_{i}, k_{i}\right)\right) & \min \sum_{i=1}^{c} E\left(T C\left(P_{i}\right)\right) \\
\text { Subject to } & Q_{i}>0, k_{i}>0 & P_{i}>\mu_{i} \\
& c_{i}>0, o_{i}>0, a_{i}>0, s_{i}>0, \mu_{i}>0
\end{array}
$$

where $Q_{i}$ is the optimal quantity to supply of component $\mathrm{i}$ (in units), $k_{i}$ is a standardized percentile of the probabilistic distribution of DLT of component $\mathrm{i}$ (without unit), $\mathrm{P}_{\mathrm{i}}$ is the optimal quantity of supply of component i (in units), while that $\mu_{i}$ and $\sigma_{i}$ are conditional mean and standard deviation (SD) gives in (7).

\section{Financial indicators applying inventory control models in food service}

Income earned for a year through the components used in the menus can be calculated with the methodology proposed by [33]. For this model we considered the maximum annual $\mathrm{CM}$ is the difference between the annual income and minimum annual TC generated by the inventory control models applied to each 
component. The expected value of the annual report to optimize a set of components for $\mathrm{i}=1, \ldots, \mathrm{c}$, $\mathrm{CM}$ is given by equation (8)

$$
\max \left\{\sum_{i=1}^{c} E\left(C M_{i}\right)\right\}=\sum_{i=1}^{c} E\left(I_{i}\right)-\min \left\{\sum_{i=1}^{c} E\left(T C_{i}\right)\right\}
$$

Where $\mathrm{E}\left(\mathrm{TC}_{\mathrm{i}}\right)=\mathrm{E}\left(\mathrm{C}_{\mathrm{i}}+\mathrm{O}_{\mathrm{i}}+\mathrm{A}_{\mathrm{i}}+\mathrm{S}_{\mathrm{i}}\right)$ and $\mathrm{CM}_{\mathrm{i}}, \mathrm{I}_{i}$ and $\mathrm{CT}_{i}$ denoted the $\mathrm{CM}$, the income and TC of component $i$ of the inventory assortment of food service, respectively. The general equation five in (8) must be specified for each type of inventory control model according to the statement below.

Continues review model. For this model is considered a subset of the total of c components inventory assortment of food service. This subset has components corresponding to grocery taken from the set $I=\{1, \ldots, \mathrm{c}\}$ and components denoted by $j=1, \ldots, \mathrm{a}<\mathrm{c}$. Thus, the expected annual TC for a component $j$ to be minimized under this model is expressed as equation (9)

$$
E\left(T C\left(k_{j}, Q_{j}\right)\right)=365 \mu_{j} c_{j}+\left(\frac{Q_{j}}{2}+r_{j}-E\left(D_{j}\right)\right) a_{j}+\frac{365 \mu_{j}}{Q_{j}} o_{j}+S\left(r_{j}\right) \frac{365 \mu_{j}}{Q_{j}} s_{j}
$$

where $E\left(D_{j}\right)$ is the expected value of DLT of component $\mathrm{j}$ give in (2), that depend of $\mu_{j}$, the correspond to the rate of DPUT conditional to demand of other component or menu. On the one hand, note that $\mu_{j}$ is multiplied by 365 because the TC is defined on an annual basis and $\mu_{j}$ on a daily basis. On the other hand, $E\left(D_{j}\right)$ need not multiply by 365 because its scope is verified within each cycle safety stock. For the CT expected given in equation (9), is considered a safety stock (SS) given by $S S_{j}=r_{j}-E\left(D_{j}\right)=k_{j}\left(\operatorname{Var}\left(D_{j}\right)^{1 / 2}\right.$. The SS corresponds to the multiplication of (3) for the safety factor $\mathrm{k}_{\mathrm{j}}$ associated with a service level of $\mathrm{q} \%$ (or amount of $\mathrm{SD}_{\mathrm{s}} \mathrm{DLT}$ ) for $0<\mathrm{q}<1$ - Note that $\mathrm{k}_{\mathrm{j}}$ is a percentile $q \%$ standardized associated with the probability distribution of the DLT component $\mathrm{j}$, established to ensure a level of service which is usually often 95\% and default by the administrator inventory. Also note that $\left(\mathrm{q}_{\mathrm{j}} / 2\right)+\mathrm{SS}_{\mathrm{j}}$ is the average component stored $\mathrm{j}$. Also, $S\left(R_{j}\right)$ is the function of the component shortage $\mathrm{j}$ defined as equation (10)

$$
S\left(r_{j}\right)=\int_{r_{j}}^{m}\left(d_{j}-r_{j}\right) f_{D_{j}}\left(d_{j}\right) \mathrm{d} d_{j}
$$

where $m$ is the maximum DLT, $\mathrm{f}_{\mathrm{Dj}}$, the PDF give in (1) and $r_{j}$ the re-order point where should make a new order purchase defined as equation (11)

$$
r_{j}=\mu_{j} l_{j}+k_{j} \sqrt{l_{j}} \sigma_{j}
$$

with $l_{j}$ as the LT of component $\mathrm{j} \mathrm{y}$ assumed as a constant. Note that to model the shortages produced by the DLT it has been assumed that the variable $D_{j}$ has Gaussian distribution [46] . In this case and assuming a service level of $95 \%$, the expressions given in equation(10) and equation (11) are reduced to equation (12) and equation (13), respectively

$$
\begin{gathered}
\mathrm{S}\left(\mathrm{r}_{j}\right)=\sigma_{j} \sqrt{l_{j}} \varnothing(1,96)-1,96 \sigma_{j} \sqrt{l_{j}} \phi(1,96) \\
r_{j}=\mu_{j} l_{j}+1,96 \sqrt{l_{j}} \sigma_{j}
\end{gathered}
$$

Perishable in a single period model. Similarly to the previous model, this model considers a subset of the total of c components corresponding to perishable products such as fruits, vegetables and meats from the set $I=\{1, \ldots, c\}$ and that components denoted by $j=$ $1, \ldots, p<c$. This model uses the approach $Q_{j} \approx P_{j}$, corresponding to an amount of component $j$ to order, able to cover a single period. According to Geunes et al. (2001), in models of inventory control of this type the reorder point $r_{p j}$ is calculated considering that the probability in-stock component $j$ corresponds to a critical ratio given by the relationship between unit costs to order a unit less to meet demand $\left(C_{u j}\right.$ $=$ underage cost) in relation to the sum of $C_{u j}$ and the cost of over-supply the demand with a more component unit $j\left(C_{o j}=\right.$ overage cost $)$, given by $\phi\left(r p_{j}\right)=C_{u j} /\left(C_{u j}+C_{o j}\right)$

In this case, $\mathrm{C}_{\mathrm{uj}}=\mathrm{s}_{\mathrm{j}}-\mathrm{a}_{\mathrm{j}} \mathrm{P}_{\mathrm{j}} /\left(365 \mu_{\mathrm{j}}\right)$ and $\mathrm{C}_{\mathrm{oj}}=\mathrm{a}_{\mathrm{j}} \mathrm{P}_{\mathrm{j}} /$ $\left(365 \mu_{\mathrm{j}}\right)$, thus equation $(14)$

$$
C_{u j} /\left(C_{u j}+C_{o j}\right)=\left(s_{j}-\left(P_{j} a_{j} / 365 \mu_{j}\right)\right) / s_{j}
$$

Applying the quantile function normal standard $\varphi^{-1}$ to (14), we obtain the re-order point in equation (15)

$$
r p_{j}=\phi^{-1}\left(C_{u j} /\left(C_{u j}+C_{o j}\right)\right)=\phi^{-1}\left(s_{j}-P_{j} a_{j} / 365 \mu_{j}\right) / s_{j}
$$


The interpretation is equivalent to $r_{j}$ in continues review give in (13), which indicates that the replenishment of component $j$ it should be performed when the stock level is just below this value, considering a safety stock comprised of the difference between this point and the DLT expected, given by $r p_{j}-\mu_{j} l_{j}$. Thus, the expected annual TC for component $\mathrm{j}$ to be minimized in equation (16)

$$
\begin{aligned}
& E\left(T C\left(P_{j}\right)\right)=365 \mu_{j} c_{j}+\left(\left(P_{j} / 2\right)+r p_{j}-\mu_{j} l_{j}\right) a_{j}+ \\
& \left(365 \mu_{j} o_{j} / P_{j}\right)+S\left(r p_{j}\right)\left(365 \mu_{j} s_{j} / P_{j}\right)
\end{aligned}
$$

In the TC expressed in equation (16), $S\left(r p_{j}\right)$ correspond to shortage function to the component $j$ produced by DLT in the model, and defined as in equation (12) and give for equation (17)

$$
S\left(r p_{j}\right)=\int_{r p_{j}}^{m D}\left(d_{j}-r p_{j}\right) f_{D_{j}}\left(d_{j}\right) \mathrm{d} d_{j}
$$

where $m \mathrm{D}$ correspond to maximum DLT in single period and $f_{d j}$ is the PDF normal for the DLT. In this case, and assumed a level of service give for $\left(P_{j}-\mu_{\mathrm{j}}\right.$ $\left.\mathrm{l}_{\mathrm{j}}\right) /\left(\sigma_{\mathrm{j}}\left(\mathrm{l}_{\mathrm{j}}\right)^{1 / 2}\right)$, the expression gives in equation (17) and equation (15) transformed in equation (18)

$S\left(r p_{j}\right)=\sigma_{j} \sqrt{l_{j}} \varnothing\left(\frac{P_{j}-\mu_{j} l_{j}}{\sigma_{j} \sqrt{l_{j}}}\right)-\left(r p_{j}-\mu_{j} l_{j}\right)\left(1-\phi\left(\frac{P_{j}-\mu_{j} l_{j}}{\sigma_{j} \sqrt{l_{j}}}\right)\right)$

\section{Summary of methodology}

Algorithm 1 summarizes the proposed methodology in six steps divided in 13 sub-steps- This steps are based in aspects revised previously in this section.

Algorithm 1. Methodology for optimizing an inventory of food service

1: Collect data of daily demand of component $i$ during a period.

2: To statistical analysis:

2.1 Make a study of correlations and autocorrelations of data obtained in step 1, examining the Pearson correlation matrix and graphs autocorrelation functions (ACF) and partial autocorrelation (PACF). This is done to detect possible statistical dependence and temporal structure of the data. If autocorrelation is detected, it must be removed using appropriate techniques. If there are no significant correlations with other components or menus demands, nor relevant autocorrelation, proceed according [33]. If only it detects a correlation between the demands of components or menus:

2.2 Suggest univariate normal distributions to demand data for components and menus that are significantly correlated.

2.3 Estimate the parameters of the distributions proposed in step 2.2.

2.4 Estimate the conditional mean and SD of the variable of interest given in (7), conditioning in all the sample values of the associated variable.

2.4 For non-conditional demand of component only considered parameter of univariate normal distributions.

3: To inventory control model:

3.1 Select the appropriate model inventory based on the type of component $j$, with $j=1, \ldots, a<c$ for groceries, and $j=1, \ldots, p<c$ for perishable components (such as meats, fruits and vegetables). 3.2 Find the optimal elements selected models inventories, based on the estimated parameters of the conditional distributions established in the step 2.4, and assuming normal for DLT.

3.3 Find the optimal elements selected models inventories, based on the estimated parameters of the univariate normal distributions established in step 2.5, and assuming normal for DLT.

4: To analysis of financial indicators:

4.1 Calculate the expected TC for the component according to the optimal policy established in step 3.2 for demand with statistical dependence and step 3.3 to demand without statistical dependence. 4.2 Obtain the CMs for component, subtracting the TCs of step 4.1 to the income for component obtain according [33].

4.3 Repeat the step from 2.4 to 4.2 , and selected the optimal value of CM for component in form conditional to the demand of other component or menu and formed independently.

5: Iterate the step 1-4 to completed $c$ components. 6: Established the optimal CMs with and without statistical dependence and compare with non-optimal.

\section{CASE STUDY}

\section{Data}

36 data demands for 7 menus that required 9 components, collected during 6 months in a SAN of Valparaiso, Chile. Data refer to food service to workers serving a Chilean regional hospital anonymous. This shows CMs food service average 
around $30 \%$ of sales, based on a medium-low socioeconomic level. The data belong to DIUV 14/2009 project, funded by the Research of the University of Valparaiso, Chile.

\section{Statistical analysis and results}

A graphical autocorrelation analysis detected that the corresponding autocorrelations are very small, so that dependence in the time can be discarded as well. This graphical analysis can be corroborated by the Durbin-Watson test and its bootstrapped $\mathrm{p}$-value to examine independence in these data. Table 1 presents a descriptive statistics based on the mean, SD and coefficient of variation (CV) of the component or menu DPUT indicated by removing the zeros of the sample. Table 2 provides the sample correlations that are significantly greater than zero ( $p$-value $<0.05$ ) between a component and another component or menu. These correlations are the highest value among all correlations between a component and another component or menu. Figure 1 shows quantile-quantile plots (QQ) normal marginal distributions fitted to the data of the components DPUTs study. We must highlight that in general the normal distribution appears to be a reasonable model to describe these data. Table 3 provides rates DPUTs for each component of the set $\mathrm{I}=\{1, \ldots$, 9\} conditional to the demand for another component or correlated menu $\left(\mu_{i}\right)$ and SDs conditional $\left(\sigma_{i}\right)$. Note that the mean and SDs without considering statistical dependence are shown in Table 1.

Table 1. Descriptive statistical of DPUTs of component or menu indicated.

\begin{tabular}{|c|c|c|c|c|c|}
\hline $\begin{array}{c}\text { Comp. } \\
\text { /Menu } \\
\text { (un/day) }\end{array}$ & $\begin{array}{c}\text { Mean } \\
\text { (un/day) }\end{array}$ & $\begin{array}{c}\text { Min } \\
\text { (un/day) }\end{array}$ & $\begin{array}{c}\text { Max } \\
\text { (un/ } \\
\text { day) }\end{array}$ & $\begin{array}{c}\text { SD } \\
\text { (un/day) }\end{array}$ & CV \\
\hline c1 & 67,94 & 24 & 135 & 29,32 & 0,43 \\
\hline $\mathrm{c} 2$ & 22,56 & 12 & 31 & 6,64 & 0,29 \\
\hline $\mathrm{c} 3$ & 46,5 & 38 & 55 & 5,76 & 0,12 \\
\hline $\mathrm{c} 4$ & 43,45 & 24 & 51 & 11,69 & 0,26 \\
\hline $\mathrm{c} 5$ & 10,79 & 2 & 42 & 10,69 & 0,99 \\
\hline $\mathrm{c} 6$ & 25,07 & 5 & 44 & 15,54 & 0,62 \\
\hline $\mathrm{c} 7$ & 8,68 & 4 & 14 & 3,19 & 0,37 \\
\hline $\mathrm{c} 8$ & 34,57 & 4 & 65 & 19,27 & 0,56 \\
\hline $\mathrm{c} 9$ & 33,69 & 5 & 68 & 28,37 & 0,84 \\
\hline $\mathrm{m} 1$ & 443,5 & 398 & 481 & 26,84 & 0,06 \\
\hline $\mathrm{m} 2$ & 389,63 & 276 & 444 & 65,07 & 0,17 \\
\hline $\mathrm{m} 3$ & 387,63 & 230 & 497 & 99,28 & 0,26 \\
\hline $\mathrm{m} 4$ & 375 & 187 & 469 & 113,92 & 0,3 \\
\hline $\mathrm{M}$ & 197 & 86 & 410 & 97,31 & 0,49 \\
\hline $\mathrm{m} 6$ & 419,1 & 380 & 460 & 28,53 & 0,07 \\
\hline $\mathrm{m} 7$ & 383,88 & 160 & 490 & 138,93 & 0,36 \\
\hline
\end{tabular}

Table 2. Pearson correlation sample coefficients between components and menus.

\begin{tabular}{|c|c|c|c|c|c|c|c|c|c|}
\hline & c1 & c2 & c3 & c4 & c5 & c6 & c7 & c8 & C9 \\
\hline $\mathbf{c 3}$ & 0,76 & & & & & & & & \\
\hline $\mathbf{m 1}$ & & & & & & & & & 0,99 \\
\hline $\mathbf{m 2}$ & & & & & & 0,95 & & 0,91 & \\
\hline $\mathbf{m 3}$ & & & & & 0,65 & & & & \\
\hline $\mathbf{m 4}$ & & & & & & & 0,75 & & \\
\hline $\mathbf{m 5}$ & & 0,82 & & & & & & & \\
\hline $\mathbf{m 6}$ & & & 0,99 & & & & & & \\
\hline $\mathbf{m 7}$ & & & & 0,99 & & & & & \\
\hline
\end{tabular}

Tables 4 and 5 show comparative indicators and financial results of incomes, costs and annual MCs of j components subset inventory control models of continuous review and perishables in a single period, according to the consideration of statistical dependence of DPUTs of components. To obtain these results the following costs are valid for the entire set of components: $a_{i}=0,042$ $\mathrm{USD} /$ cyclexunit, $c_{i}=0,6 \mathrm{USD} / \mathrm{unit}_{i}=0,33 \mathrm{USD} /$ unit and $o_{i}=0.86 \mathrm{USD} /$ cycle. The policies proposed supply produce an annual MC of 238,770.79 USD/year, applying inventory control models continuous review and perishable in single period for the components, considering the statistical dependence of DPUT. While not considering dependence on DPUTs of components, the CMs alone reaches to 218,635.67 USD/year. Comparing these CMs optimized to food service, obtained with the proposed methodologies concerning the $\mathrm{CM}$ actual annual showing this food service, which is 201805.9 USD/year, an optimization of an $18.32 \%$ and $8,34 \%$ was obtained, applying there inventory control models with and without dependence of DPUTs of components, respectively.

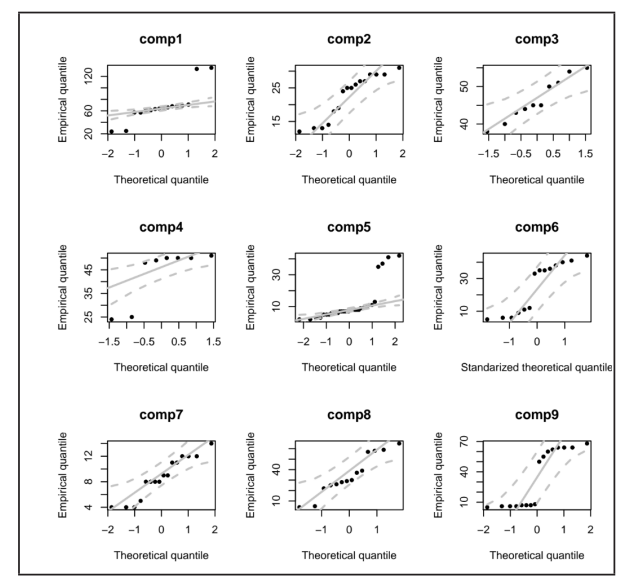

Figure 1. QQ Plot of normal marginal distributions fitted to data of 9 components. 
Table 3. Conditional rate of DPUT of component i ( $\mu$ i) and conditional $\mathrm{SD}(\sigma \mathrm{i})$.

\begin{tabular}{|c|c|c|}
\cline { 2 - 3 } \multicolumn{1}{c|}{} & \multicolumn{2}{c|}{ Statistical indicator } \\
\hline Component & $\boldsymbol{\mu}_{\boldsymbol{i}}$ (un/day) & $\boldsymbol{\sigma}_{\mathbf{i}}$ (un/day) \\
\hline $\mathbf{c 1}$ & 35,21 & 14,49 \\
\hline $\mathbf{c 2}$ & 10,71 & 2,85 \\
\hline $\mathbf{c 3}$ & 38,32 & 2,84 \\
\hline $\mathbf{c 4}$ & 34,49 & 0,83 \\
\hline $\mathbf{c 5}$ & 3,18 & 6,36 \\
\hline $\mathbf{c 6}$ & 12,74 & 3,47 \\
\hline $\mathbf{c 7}$ & 23,09 & 1,59 \\
\hline $\mathbf{c 8}$ & 19,91 & 5,78 \\
\hline $\mathbf{c 9}$ & 24,79 & 2,83 \\
\hline
\end{tabular}

Table 4. Comparative indicators and financial results to component indicated to perishable in single period inventory control model according statistical dependence of DPUTS.

\begin{tabular}{|c|c|c|c|c|c|c|c|}
\hline \multirow{2}{*}{$\begin{array}{c}\text { Statistical dependence } \\
\text { of DPUT }\end{array}$} & \multirow{2}{*}{$\begin{array}{l}\text { Statistical } \\
\text { indicator }\end{array}$} & \multicolumn{6}{|c|}{ Component } \\
\hline & & comp $_{1}$ & comp $_{2}$ & comp $_{5}$ & $\mathrm{comp}_{6}$ & $\mathrm{comp}_{7}$ & $\mathrm{comp}_{8}$ \\
\hline \multirow[t]{6}{*}{ Yes } & $P_{j}$ (units) & 106 & 32 & 10 & 38 & 69 & 60 \\
\hline & $r p_{j}$ (units) & 3,07 & 3,08 & 3,06 & 3,08 & 3,08 & 3,08 \\
\hline & $S\left(r p_{j}\right)$ (units shortage/cicle) & 0,47 & 0 & 5,36 & 0 & 0 & 0 \\
\hline & $\mathrm{E}\left(I_{j}\right)(\mathrm{USD} /$ year $)$ & 49431,16 & 15036,66 & 4469,24 & 17878,55 & 32417,31 & 27960,61 \\
\hline & $\mathrm{E}\left(\mathrm{CT}\left(P_{j}\right)\right)(\mathrm{USD} /$ year $)$ & 7832,26 & 2449,86 & 1026,58 & 2893,09 & 5160,49 & 4641,59 \\
\hline & $\mathrm{E}\left(\mathrm{MC}_{j}\right)$ (USD/year) & 41598,9 & 12586,8 & 3442,66 & 14985,46 & 27256,82 & 23319,02 \\
\hline \multirow[t]{6}{*}{ Not } & $P_{j}$ (units) & 204 & 68 & 32 & 75 & 27 & 104 \\
\hline & $r p_{j}$ (units) & 3,07 & 3,08 & 3,06 & 3,08 & 3,08 & 3,08 \\
\hline & $S\left(r p_{j}\right)$ (shortage units/cicle) & 1,3 & 0 & 7,53 & 2,85 & 0,037 & 3,42 \\
\hline & $\mathrm{E}\left(I_{j}\right)(\mathrm{USD} /$ year $)$ & 65862,42 & 21873,35 & 10464,42 & 24305,65 & 8422,149 & 33515,48 \\
\hline & $\mathrm{E}\left(\mathrm{CT}\left(P_{j}\right)\right)(\mathrm{USD} /$ year $)$ & 15032,22 & 5044,73 & 2764,77 & 5761,95 & 2008,23 & 7815,07 \\
\hline & $\mathrm{E}\left(\mathrm{MC}_{j}\right)(\mathrm{USD} /$ year$)$ & 50830,2 & 16828,62 & 7699,65 & 18543,55 & 6413,919 & 25700,41 \\
\hline
\end{tabular}

Table 5. Comparative indicators and financial results to component indicated to continues review inventory control model according statistical dependence of DPUT.

\begin{tabular}{|c|c|c|c|c|}
\hline \multirow{2}{*}{$\begin{array}{c}\text { Statistical dependence } \\
\text { of DPUT }\end{array}$} & \multirow{2}{*}{$\begin{array}{l}\text { Statistical } \\
\text { indicator }\end{array}$} & \multicolumn{3}{|c|}{ Component } \\
\hline & & $\operatorname{comp}_{3}$ & comp $_{4}$ & $\operatorname{comp}_{9}$ \\
\hline \multirow[t]{6}{*}{ Yes } & $Q_{j}$ (units) & 759 & 719 & 610 \\
\hline & $k_{j}$ (without units) & 2,47 & 2,45 & 2,39 \\
\hline & $S\left(r_{j}\right)$ (shortage units/cicle) & 0,011 & 0 & 0,013 \\
\hline & $\mathrm{E}\left(I_{j}\right)(\mathrm{USD} /$ year $)$ & 53804,58 & 48422,09 & 34811,59 \\
\hline & $\mathrm{E}\left(\mathrm{CT}\left(P_{j}\right)\right)(\mathrm{USD} /$ year$)$ & 8426,03 & 7584,3 & 5456,8 \\
\hline & $\mathrm{E}\left(\mathrm{MC}_{j}\right)(\mathrm{USD} /$ year$)$ & 45378,55 & 40847,79 & 29354,79 \\
\hline \multirow[t]{6}{*}{ Not } & $Q_{j}$ (units) & 837 & 812 & 726 \\
\hline & $k_{j}$ (without units) & 2,5 & 2,49 & 2,44 \\
\hline & $S\left(r_{j}\right)$ (shortage units/cicle) & 0,02 & 0,04 & 0,12 \\
\hline & $\mathrm{E}\left(I_{j}\right)(\mathrm{USD} /$ year $)$ & 45079,71 & 42050,16 & 32658,55 \\
\hline & $\mathrm{E}\left(\mathrm{CT}\left(P_{j}\right)\right)(\mathrm{USD} /$ year$)$ & 10219,7 & 9535,33 & 7413,07 \\
\hline & $\mathrm{E}\left(\mathrm{MC}_{j}\right)(\mathrm{USD} /$ year $)$ & 34860,01 & 32514,83 & 25245,48 \\
\hline
\end{tabular}




\section{CONCLUSIONS}

The proposed methodology showed an optimum way for food contribution margins between components or menus, and programming stochastic inventory models. To describe the parameters used in programming stochastic inventory models used, were used probabilistic distributions to joint demands of components and menus, assuming a bivariate normal distribution. This choice is supported in that the vast majority of inventory models studied in literature to optimize inventory TCs, have been based on the assumption distributions probabilistic modeling univariate normal random variables of demand per unit time and demand during the lead time [16].

The results in the case study of this review show a significant improvement in margins contribution in food-service. In the case with dependent demand margins contributions increased from $30 \%$ to $35,5 \%$. Case study results agree with the authors mentioned in [29], who, occupying linear programming models, related minimizing total costs inventories maximizing contribution margins in critical products assortment of inventory. In both cases compared, the amounts fixed to supply components such stores by inventory models continuous review, were considerably higher than the rates of conditional demand estimated. This is explained as follows: groceries can be stored for a while and then prolonged inventory RC models this condition is used to decrease the cost of generating an order, and that this cost does not depend on quantities ordered. The components that occupy the perishable inventory model in a single period presented an optimized amount to supply similar to the quantity demanded. This of must to expire quickly such materials (including fruits, vegetables and meats), with a period storage does not allow prolonged. Therefore, this model should inventory be quite successful for such components, with a bounded replacements and levels minimum stock levels in storage. This contributes to reducing storage costs compared to what happened in practice before making optimization [16]. In future studies it is possible to obtain improvements in the methodology proposed in this paper on regards vof: (i) multivariate modeling occupying marginal probability distributions raised other than the Gaussian or normal; (ii)consideration of zero values in modeling demand components, something that occurs with high frequency in demand and data necessary to model with probability distributions zero-inflated [21]; and (iii) the use of autoregressive moving average components and for model the temporal dependence.

\section{ACKNOWLEDGEMENTS}

This research was partially funded by "GrantsCONICYT" of the National Commission for Scientific and Technological Research (CONICYT) government of Chile.

\section{REFERENCES}

[1] M. L. Ahlstrom, D. Bartlett, C. Collier, J. Duchesne, D. Edelson, A. Gesino and J. O'Sullivan. "Knowledge is power: Efficiently integrating wind energy and wind forecasts". Power and Energy Magazine, IEEE. Vol. 11 $\mathrm{N}^{\circ}$ 6, pp. 45-52. 2014.

[2] M. Barros, V. Leiva, R. Ospina and A. Tsuyuguchi. "Goodness-of-fit tests for the Birnbaum-Saunders distribution with censored reliability data". IEEE Transactions on Reliability. Vol. 63, pp. 543-554. 2014.

[3] M. Ben-Daya and A. Raouf. "Inventory models involving lead time as a decision variable". Journal of the Operational Research Society. Vol. 45, pp. 579-582. 1994.

[4] R. Botter and L. Fortuin. "Stocking strategy for service parts: A case study". International Journal of Operations and Production Management. Vol. 20, pp.656-674. 2000.

[5] M. Braglia, A. Eaves and B. Kingsman. "Forecasting for the ordering and stockholding of spare parts". Journal of the Operational Research Society. Vol 55, pp.431-437. 2004.

[6] M. Braglia, A. Grassi and R. Montanari. "Multi-attribute classification method for spare parts inventory management". Journal of Quality in Maintenance Engineering. Vol. 10, pp.55-65. 2003

[7] B.G. Brown, R.W. Katz and A.H. Murphy. "Time series models to simulate and forecast wind speed and wind power". Journal of Climate and Applied Meteorology. Vol. 23, pp. 1184-1195. 1984

[8] P. Carter, J. Carter, R. Monczka, T. Slaight. and A.Swan. "The future of purchasing and 
supply: A ten-year forecast." Journal of Supply Chain Management. Vol. 36, pp.14-26. 2000.

[9] B. Cobb, R. Rumí and A. Salmerón. "Inventory management with log-normal demand per unit time". Computers and Operations Research. Vol. 40, pp.1842-1851. 2013

[10] G. Eppen, F. Gould, C. Schmidt, J. Moore and L. Weatherford. "Operational Research in Management Sciences". Prentice-Hall, Mexico. 2004.

[11] G. Giebel, R. Brownsword, G. Kariniotakis, M. Denhard and C. Draxl. "The state of the art in short term prediction of wind power: A literature overview". Technical report, ANEMOS. Plus. 2011

[12] J. Geunes, R. Ramasesh and J. Hayya. (2001). "Adapting the newsvendor model for infinitehorizon inventory systems". International Journal of Production Economics. Vol. 72, pp.237-250. 2001

[13] J. Gjerdrum, N. Samsatli, N. Shah and L. Papageorgiou. "Optimisation of policy parameters in supply chain applications". International Journal of Logistics Research and Application. Vol. 8, pp.15-36. 2005.

[14] D. Grant, C. Karagianni and M. Li. "Forecasting and stock obsolescence in whisky production". International Journal of Logistics Research and Application. Vol. 9, pp.319-334. 2006

[15] J. Hayya, U. Bagchi, J. Kim and D. Sun. "On static stochastic order crossover". International Journal of Production Economics. Vol. 114, pp.404-413. 2008

[16] F. Hillier and G. Lieberman.” Introduction to Operational Research". McGraw Hill, New York, US. 2005.

[17] N. Johnson, S. Kotz and N. Balakrishnan. "Continuous Univariate Distributions", Wiley, New York, US. Vol.1. 1994

[18] N. Johnson, S. Kotz and N. Balakrishnan. "Continuous Univariate Distributions", Wiley, New York, US. Vol.2. 1995

[19] K. Kogan and H. Tell. "Production smoothing by balancing capacity utilization and advance orders". Journal of Business Logistics. Vol. 41, pp.223-231. 2009

[20] S. Kotz, N. Balakrishnan and N. Johnson. "Continuous Multivariate Distributions", Wiley, New York, US. Vol.1. 2000
[21] V. Leiva, M. Santos-Neto, F.J.A. Cysneiros and M. Barros. "A methodology for stochastic inventory models based on a zero-adjusted Birnbaum-Saunders distribution”. Applied Stochastic Models in Business and Industry. Vol. 32, pp.74-89. 2016

[22] O. Lorenzo. "A comprehensive review of enterprise system (ES) research". Academia Revista Latinoamericana de Administración. Vol. 33, pp.34-51. 2004.

[23] J. K. Møller, H.A. Nielsen, And H. Madsen. "Time-adaptive quantile regression". Computational Statistics \& Data Analysis. Vol. 52, pp. 1292-1303. 2008.

[24] S. Nahmias. "Production and Operations Analysis". McGraw Hill, New York, US. 2001.

[25] K. Namit, and J. Chen. "Solutions to the inventory model for gamma lead-time demand". International Journal of Physical Distribution and Logistics Management. Vol. 29, pp.138-154. 1999

[26] J, Nicolau. "Leveraging profit from the fixedvariable cost ratio: The case of new hotels in Spain”. Tour Manager. Vol. 26, pp.105-111. 2009

[27] P. Pedregal. "Introduction to optimization" Springer Science \& Business Media. Vol. 6 . 2006

[28] K. V. Price, R.M Storn and J.A, Lampinen. "Differential Evolution: A Practical Approach to Global Optimization". Springer, Berlin, Germany. 2006.

[29] R. Ramanathan. "ABC inventory classification with multiple-criteria using weighted linear optimization". Computers and Operations Research. Vol. 33, pp.695-700. 2006.

[30] A. Ramirez. "A multi-stage almost ideal demand system: The case of beef demand in Colombia". Revista Colombiana de Estadística. Vol. 36, pp.23-42. 2013.

[31] F. Rojas. "Time dependence in joint replacement to multi-products grouped. the case of hospital food service". Cogent Engineering. Vol. 3. ID 1251029. 2016.

[32] F. Rojas and V. Leiva. "Inventory management in food companies with demand statistically dependent". ARLA: Academia Revista Latinoamericana de Administración, Vol.29, pp.450-488. 2016. 
[33] F. Rojas, V. Leiva, P. Wanke and C. Marchant. "Optimization of contribution margins in food services by modeling independent component demand". Revista Colombiana de Estadística Vol. 38, pp.1-30. 2015.

[34] A. Shapiro, D. Dentcheva and A. Ruszczynski. "Lectures on Stochastic Programming: Modelling and Theory", SIAM, Philadelphia, US. Vol.16. 2014.

[35] E. Silver, D. Pyke and R. Peterson, (1998). Inventory Management and Production Planning and Scheduling. Wiley. New York, US.

[36] P. J. Solomon. "Variance components". In Armitage, P. and Colton, T., editors, Encyclopaedia of Biostatistics. Wiley, Chichester. 2005.

[37] T. Speh and G. Wagenheim. "Demand and lead-time uncertainty: The impacts on physical distribution performance and management". Journal of Business Logistics. Vol. 1, pp. 95-113. 1978.

[38] J. Tastu. "Short-term wind power forecasting: probabilistic and space-time aspects". Doctoral dissertation, Technical University of Denmark. 2013.

[39] R. Thangaraj, M. Pant, P. Bouvry and A. Abraham. "Solving multi objective stochastic programming problems using differential evolution". In B. Panigrahi, S. Das, P. Suganthan, and S. Dash, editors, Swarm, Evolutionary, and Memetic Computing. Vol. 6466, pp.54-61. Springer, Berlin-Heidelberg, Germany. 2010.

[40] P. Wanke, "Consolidation effects and inventory portfolios". Transportation Research Part E: Logistics and Transportation Review. Vol. 45, pp.107-124. 2008.
[41] P. Wanke. "Product, operation, and demand relationships between manufacturers and retailers". Transportation Research Part E: Logistics and Transportation Review Vol. 48, pp.340-354. 2008.

[42] P. Wanke. "Inventory Management in Supply Chain: Decisions and Quantitative Models (in Portuguese)". Atlas, Brazil. 2011.

[43] P. Wanke. "Consolidation effects: Assessing the impact of tail dependence on inventory pooling using copulas". International Journal of Inventory Research. Vol. 2, pp.174-188. 2014.

[44] P. Wanke, R. Arkader and A, Rodrigues. A study into the impacts on retail operations performance of key strategic supply chain decisions. International Journal of Simulation and Process Modelling. Vol. 4, pp. 106-118. 2008

[45] P. Wanke, H. Ewbank, V. Leiva and F. Rojas. "Inventory management for new products with triangularly distributed demand and lead-time". Computers and Operations Research. Vol. 69, pp.97-108. 2016.

[46] P. Wanke and V. Leiva, "Exploring the potential use of the Birnbaum-Saunders distribution in inventory management". Mathematical Problems in Engineering. Article ID 827246:1-9. 2015.

[47] A. Zaldaña and M. Ayala. "Plan de Negocios para la Elaboración de Jugos Naturales a Base de Frutas y Hortalizas". Tesis de doctorado, Universidad de Chile, Facultad de Ciencias Físicas y Matemáticas. Departamento de Ingeniería Industrial, Chile. 2011. 